\title{
A feminização como tendência da migração boliviana para São Paulo
}

\author{
Clara Lemme Ribeiro*
}

\section{Introdução}

O meu interesse pelas reflexões sobre a temática de migrações e gênero começou a partir dos grupos de estudos sobre mobilidade do trabalho (GAUDEMAR, 1977) e crítica do valor-dissociação (SCHOLZ, 2004) do Laboratório de Geografia Urbana da USP (LABUR-USP). O estudo aprofundado da teoria crítica já levantava perguntas sobre a relação entre as migrações, a mobilidade e a crise do trabalho.

A aproximação com o objeto empírico aconteceu durante um intercâmbio acadêmico realizado na graduação para a Universidad Nacional de Córdoba, na Argentina. Em uma aula sobre migrações, ouvi dizer pela primeira vez que os fluxos migratórios latino-americanos estavam se feminizando. Segundo o professor, uma das tendências da migração do século XXI era o aumento de uma mobilização entre países da América Latina, e que era característico desses grupos uma participação maior de mulheres, caracterizando uma feminização.

$\mathrm{O}$ argumento quantitativo, que passava apenas pelo aumento percentual da presença feminina, não respondia a uma série de questões que me vinham à cabeça: antes, as mulheres não migravam? Ou migravam apenas para acompanhar os maridos? E se isso é verdade, o que acontece agora na vida dessas mulheres que faz com que elas deixem seus países? Ou essa mudança tem a ver com a maneira como elas são recebidas nos contextos de destino? Agora elas decidem e viajam sozinhas ou a migração feminina acontece ainda em função do marido? Os números, no entanto, pouco respondem a esse tipo de pergunta.

De volta a São Paulo-SP, passei a ouvir que o fluxo de bolivianos para essa cidadeacompanhava também a tendência do processo de feminização. O envolvimento da comunidade boliviana com o trabalho na costura já era conhecido, mas o que acontecia com as mulheres? Falando em números, já haviam ultrapassado a presença masculina? Ainda faltava descobrir se vinham trabalhar também na costura ou conseguiam outras ocupações, como acontece em outros contextos migratórios; se vinham sozinhas ou acompanhando a família; com que tipo de realidade se encontravam depois

\footnotetext{
* Geógrafa, mestranda do Programa de Pós-Graduação em Geografia Humana da USP-PPGH-USP
} 
de chegar a São Paulo. E era também crucial entender se a sua saída do país tinha a ver com um empoderamento feminino - saindo debaixo da tutela masculina - ou com uma feminização da pobreza atirando as mulheres aos lugares mais precarizados da vida social, obrigando-as a migrar para conseguirem reproduzir a si e aos seus filhos.

As pistas para responder a essas perguntas foram os estudos realizados desde antes sobre o conceito de mobilidade do trabalho (GAUDEMAR, 1977), o que diferencia as reflexões aqui apresentadas das pesquisas anteriores realizadas sobre a migração boliviana para São Paulo, como o trabalho pioneiro de Sidney Silva (1997) e os estudos posteriores de Freitas (2010) e Favaretto (2012). Para uma leitura do processo de feminização, a partir das considerações de Rezera (2012) e Almeida (2013), o caminho teórico foi traçado a partir da crítica à dissociação-valor de Scholz (2004).

A seguir, os resultados elaborados a partir da pesquisa que tentou responder a essas perguntas. Parte-se em primeiro lugar de um breve histórico da migração boliviana para São Paulo que tenta entender se houve um aumento progressivo do número de mulheres. Em seguida, apresenta-se o contexto de saída das mulheres da Bolívia e as suas trajetórias, particularmente em relação ao trabalho, após chegar em São Paulo. A partir daí, discutem-se alguns pontos cruciais das relações de gênero dentro das oficinas de costura. À guisa de conclusão, uma breve reflexão sobre o conceito de feminização das migrações.

O trabalho de campo desta pesquisa teve duas etapas: a primeira, entrevistas com mulheres bolivianas residentes em São Paulo, à época, trabalhando em oficinas de costura, realizadas entre novembro e dezembro de 2014 e em novembro de 2015; a segunda, visitas a oficinas de costura em acompanhamento aos agentes do Programa Saúde da Família ${ }^{1}$ nos bairros do Brás e do Bom Retiro, entre junho e julho de 2015.

Neste artigo, apresentamos as trajetórias de seis mulheres com quem tivemos a oportunidade de conversar ${ }^{2}$, considerando os seus contextos de saída e de inserção. Marisa, originária de um pueblo à beira do Salar do Uyuni, casada; Marcela, de Copacabana, mas residente em La Paz antes da migração, solteira; Brenda, moradora de um pueblo mineiro, solteira; Carmen, de La Paz, solteira e mãe; Denise, de El Alto, solteira; e Jéssica, de La Paz, separada e mãe.

\section{Migração boliviana para São Paulo: um histórico}

De acordo com diversos autores (SILVA, 1997; FREITAS, 2010; FAVARETTO, 2012; entre outros), o primeiro grande grupo de bolivianos se mobiliza para São Paulo entre 1950 e 1970, composto principalmente por estudantes universitários, atraídos por acordos de intercâmbio acadêmico assinados entre os Estados brasileiro e boliviano, e por profissionais liberais que tinham dificuldade de empregar-se na sociedade de origem. Naquele período, o Estado boliviano adotou uma série de medidas de modernização que buscavam alcançar 
os níveis de competitividade e produtividade dos outros países. A dificuldade de formar e manter uma classe média de profissionais liberais compõe esse cenário crítico. Segundo Freitas (2010), as medidas modernizadoras realizadas pelo Estado boliviano tiveram duas consequências fundamentais: a mobilização de trabalhadores do campo para as cidades, especialmente para as periferias, e a mobilização de profissionais liberais para fora do território boliviano.

Essa chamada primeira onda caracteriza-se principalmente por estudantes universitários, atraídos por acordos de intercâmbio acadêmico assinados entre os Estados brasileiro e boliviano, e por profissionais liberais que tinham dificuldade de empregar-se na sociedade de origem. Embora esses grupos fossem, em termos percentuais, pouco significativos para a cidade de São Paulo, tiveram grande impacto no contexto de origem. É notável que pouco se comente a presença feminina nesse momento da mobilização boliviana para São Paulo. Apenas Freitas (2010) menciona a presença de mulheres realizando trabalho doméstico remunerado.

A partir da década de 1980, a Bolívia enfrenta hiperinflação, altas dívidas externas e instabilidade política, além de uma série de desastres naturais provocados pelo fenômeno do El Niño (FREITAS, 2010; NÓBREGA, 2009; SILVA, 1997). É aí que o Estado boliviano adota, em 1985, uma série de medidas neoliberais consolidadas no Decreto $21.060^{3}$. Determina-se um rebaixamento dos preços dos produtos agrícolas, o que dificulta ainda mais as possibilidades de reprodução da população rural, que migra em ritmo acelerado para as principais cidades do país, como La Paz, Santa Cruz e Cochabamba ${ }^{4}$. Expulsão da população rural, inchaço das periferias urbanas e precarização do trabalho, além do aumento do desemprego, compõem um cenário de mobilização para fora do território boliviano, para destinos variados, principalmente a partir dos anos 1990. Aos poucos, consolidam-se fluxos migratórios para Estados Unidos, Espanha, Argentina e Brasil.

Aqui, para além das áreas de fronteira, o principal destino desses imigrantes é a cidade de São Paulo, onde o setor têxtil absorve uma parte dessa força de trabalho mobilizada como costureiros nas pequenas oficinas. Estas realizam a parte de produção da indústria de confecção, sendo o último momento de uma cadeia de terceirizações e quarteirizações que chega às lojas de roupas e aos grandes departamentos. A entrada dos bolivianos como força de trabalho barata da indústria de confecção consolida o fluxo migratório para São Paulo e a assim chamada segunda onda migratória, associada à tendência de feminização.

Durante parte dessa história, a presença feminina não tem destaque. Não aparece com relevância nas pesquisas acadêmicas ou nos relatos daquela época. Onde estavam as mulheres então? É possível que, no começo, elas viessem acompanhar os maridos, principalmente aqueles que eram profissionais liberais e chegaram entre 1950 e 1970. Mas é na década de 1990 que a presença feminina na comunidade boliviana em São Paulo passa a chamar atenção. Sidney Silva (1997) já comentava a carga dupla de trabalho das mulheres que, além de 
costurar, faziam o trabalho doméstico das oficinas. Segundo Cymbalista e Xavier (2007), em 1992, 26\% da população boliviana em São Paulo era de mulheres; em 2007, elas chegavam a 44\%. Por que há um aumento tão grande da migração de bolivianas para São Paulo entre as chamadas primeira e segunda onda? Por que há um novo aumento entre as décadas de 1990 e 2000?

\title{
Contextos de saída
}

Acontece que as políticas neoliberais bolivianas da década de 1980 reforçam e aprofundam uma desigualdade de gênero que já existia no país. 0 acesso feminino ao trabalho e ao dinheiro torna-se cada vez mais difícil. De acordo com dados da Comissão Econômica para América Latina e Caribe (CEPAL) na Bolívia ${ }^{5}$, em 2010: 37,8\% mulheres contra 11,1\% homens não recebiam o devido salário (trabalham mas não recebem); mulheres bolivianas ganhavam menos que os homens (US\$79,9 contra US\$100), desigualdade que diminui conforme o nível educacional aumenta, mas nunca se equipara; $66 \%$ das mulheres estavam ocupadas em trabalhos informais, contra $52,8 \%$ dos homens. No trabalho de Almeida (2013), ao analisar Bolívia, Peru, Paraguai e Brasil, encontramos que:

\begin{abstract}
Na América Latina, a taxa de desemprego das mulheres é superior em relação aos homens, variando de $10 \%$ a $40 \%$. Também tem aumentado o número de mulheres que inserem-se em situações precárias de trabalho, com baixos salários, ausência de contratos e proteção social, trabalho em domicílio e em subcontratos" (ALMEIDA, 2013, p. 42).
\end{abstract}

Segundo ela, a taxa de desemprego urbano por sexo na Bolívia (\%), em porcentagem é: 6,8 para homens, 7,8 para mulheres (1990); 7,3 para homens e 10,3 para mulheres (2004); 3,6 para homens, 6,2 para mulheres (2009) (ALMEIDA, 2013, p. 45). Além disso, cai sobre as mulheres a responsabilidade sobre as atividades domésticas (limpar, cozinhar, lavar roupa etc.), além do cuidado com os filhos. A obrigação de cuidar ao mesmo tempo do emprego, da casa e das crianças também cria maiores dificuldades na vida dessas mulheres, empurrando-as para trabalhos informais, precarizados e mal pagos, ou à migração.

Podemos olhar para o contexto de saída também a partir das próprias bolivianas que entrevistamos. Mulheres que nascem em áreas rurais muitas vezes mobilizam-se primeiro em direção aos grandes centros urbanos, pela dificuldade de reproduzir-se no campo. Marisa, 29 anos, nasceu no pueblo rural de Salinas, à beira do Salar do Uyuni. No entanto, na tradição patrilinear boliviana, a terra é herdada apenas pelos filhos homens e ela (Marisa), sendo negada do acesso à propriedade, muda-se com sua madrinha à cidade de Santa Cruz, onde tinham parentes. Lá, mantinha um pequeno negócio de venda de toalhas e roupões de banho, tendo muitas dificuldades de mantê-lo e obter renda suficiente para 
sustentar-se. Decide mudar-se ao Brasil com o marido em 2014, após ouvir de um vizinho que seu filho havia migrado, com o objetivo de juntar dinheiro para financiar os estudos de engenharia civil do esposo e a reabertura de seu próprio negócio. No caso de Marcela, 32 anos, a pequena propriedade onde morava, na área rural de Copacabana, pueblo à beira do Lago Titicaca, não era suficiente para manter toda a família. Ela se muda a La Paz, onde trabalhava em uma creche na qual ganhava cerca de BOL $\$ 400$ (à época, cerca de $R \$ 150$, segundo ela), quando decide vir a São Paulo, em 2009, encontrar-se com a irmã, que já morava na cidade com a filha. O plano de Marcela é juntar dinheiro para abrir um negócio próprio em La Paz, quando puder retornar.

Diferente é o caso de Brenda, 21 anos, filha de mineiro, que morava com a família a $30 \mathrm{~km}$ de Oruro, capital do departamento de mesmo nome, em um povoado adjacente à mina. $O$ pai deixava apenas que os filhos homens trabalhassem, enquanto as filhas deveriam permanecer em casa, ajudar a mãe nas tarefas domésticas e esperar o casamento. É por isso que ela migra diretamente para São Paulo, sem passar por nenhuma grande cidade boliviana. Em 2013, vai para encontrar os irmãos, onde poderia trabalhar na costura e guardar dinheiro para pagar seus estudos universitários.

$\mathrm{O}$ caso das mulheres oriundas das periferias urbanas compõe o mesmo quadro. Carmen, 33 anos, nascida na cidade de La Paz, trabalha desde os oito anos de idade para manter a si mesma e aos irmãos mais novos. Depois que se separa do marido e começa a criar a filha sozinha, tem muita dificuldade em cuidar da menina e trabalhar ao mesmo tempo. Não conseguia levar a filha ao trabalho nem ter ajuda de alguém que cuidasse dela. Viaja ao Brasil pela primeira vez para ver como são as condições de trabalho e de vida. Depois de um ano, retorna à Bolívia para buscar a filha e levá-la para São Paulo, já decidida a ficar na cidade por mais alguns anos. Já Denise, 22 anos, da cidade de El Alto, periferia de La Paz, não conseguia conciliar o emprego e os estudos universitários de agronomia, perdendo o primeiro ano de faculdade. Sem conseguir ter dinheiro para retomar os estudos e se manter, decide trabalhar em São Paulo com os tios, donos de uma oficina. Vem para o Brasil em 2014, com o plano de ficar dois anos e então retornar.

Gabriela, com a mesma idade e também de El Alto, tem outra trajetória: migra para São Paulo em 2008 com os pais e a irmã mais nova. Alguns anos antes, a irmã mais velha de Gabriela tinha decidido vir à cidade para trabalhar, depois de conversar com vizinhos que tinham uma oficina de costura. Seu pai permite que ela viaje apenas acompanhada do irmão. Segundo ela, o problema do país naquele momento não era o desemprego, mas a inflação: "trabalho a gente tinha, meu pai tinha trabalho, mas o preço das coisas subia muito" (Gabriela). É por isso que depois de algum tempo a família vem se juntar aos filhos, que já começavam a juntar dinheiro. Se endividam para comprar algumas máquinas de costura e montar a própria oficina com trabalho apenas familiar. Com o tempo, se estabelecem em São Paulo e já nem pensam em voltar para a Bolívia, nem para visitar. 
Selma, 36 anos, sente o oposto em relação ao país de origem: desde 2000 em São Paulo, sente-se até hoje como estrangeira e gostaria de retornar, mas se mantém pelas filhas, que nasceram aqui. Ela morava na periferia de La Paz e migra para conseguir trabalhar e ganhar mais; viaja com o primo porque não podia fazê-lo sozinha. O sonho de voltar para a Bolívia esteve sempre presente, mas quer que as duas filhas, de 12 e 15 anos, aproveitem as oportunidades do Brasil.

Há mais um motivo pelo qual as bolivianas decidem mobilizar-se para fora do país. Casos de violência doméstica e sexual também se tornam razão para a migração, como nos relatou Jéssica, 32 anos, de La Paz. Após sofrer um estupro em Cochabamba, onde então morava, é trazida pelos irmãos para trabalhar na oficina de costura da qual eram donos. Durante a estadia em São Paulo, ela engravida e poucos meses depois retorna à Bolívia. Cinco anos depois, em 2015, vem mais uma vez à cidade, trazendo o filho para que conheça seu pai. Além disso, Jéssica é formada em odontologia e migra buscando um salário melhor como dentista e a possibilidade de fazer uma especialização na sua área. Segundo ela, esse tipo de oportunidade não existe em seu país.

Entre as causas relatadas pelas próprias mulheres estão, portanto, as dificuldades no acesso ao trabalho e ao dinheiro, seja pela impossibilidade de manter-se no campo, seja pela baixa remuneração dos trabalhos considerados femininos, como aconteceu com Marcela., ou pela dificuldade de encontrar um trabalho que permita a conciliação com os estudos ou com o cuidado dos filhos. A fuga de uma situação de violência de gênero também é uma causa de migração.

As configurações familiares também marcam as decisões de migração. Elas podem vir sozinhas, acompanhadas do marido, de algum parente (irmãos, primos, tios) ou de toda a família, ou ainda vir trazendo seus filhos. Essas configurações redefinem as suas trajetórias e projetos migratórios, inclusive as possibilidades de permanência e retorno. Em geral, as mulheres que se sentem mais isoladas em relação ao grupo familiar sentem mais vontade de voltar. Às vezes, é o estabelecimento de uma família em São Paulo que faz com que fiquem. Marisa, como soubemos depois, retornou com o marido à Bolívia quando engravidou, porque queria ter e criar lá a sua criança. No caso de Carmen, a migração está profundamente ligada à possibilidade de poder cuidar da sua filha. As estratégias de reprodução são múltiplas e variadas, mas estão sempre ligadas aos arranjos familiares, ao controle por parte dos pais, ao cuidado com os filhos e aos papeis que devem ocupar as mulheres dentro desses arranjos.

\section{Contextos de inserção}

Atualmente, a maioria das mulheres bolivianas que se mobilizam para São Paulo se inserem no universo da costura, se não como costureiras, como faxineiras, cozinheiras, ajudantes nas mesmas oficinas, ou ainda como vendedoras de roupa ${ }^{6}$. Trata-se de empregos informais, com longas jornadas de 
trabalho e, no caso da costura, com remuneração por produtividade. O contrato de emprego também inclui a oferta de moradia no mesmo local de trabalho, o que aumenta a exposição destas mulheres, principalmente as mais novas, a casos de assédio e abuso sexual. O perfil destas mulheres é extremamente variável em relação a idade, estado civil, ocupação anterior, origem rural ou urbana e nível de escolaridade. $O$ projeto migratório no qual estão envolvidas também varia, podendo ser individual ou familiar, temporário ou permanente e, inclusive, podendo transformar-se ao longo do processo migratório. A chegada em São Paulo é acompanhada de várias mudanças, especialmente no que se refere ao trabalho.

Muitas bolivianas, ao chegar na oficina de costura, começam a trabalhar nos postos de cozinheira ou faxineira, que recebem bem menos que os costureiros. Selma e a irmã mais velha de Gabriela passaram por isso. Acompanhadas por um homem, enquanto ele logo aprendeu o ofício da costura, elas estiveram muito tempo trabalhando nessas atividades pouco remuneradas, consideradas femininas, até poderem se dedicar ao trabalho produtivo.

Acontece muito, também, a troca de oficinas de costura por motivos diversos. Pode ser por não gostar da casa, achar que o valor pago por peça não vale a pena, por problemas com pagamento ou por brigas pessoais entre costureiros. Marisa, por exemplo, durante quase dois anos que esteve no Brasil, trocou de oficina diversas vezes. Da primeira saiu porque pagavam a ela e ao marido um valor por peça menor que o dos outros costureiros; da segunda, saiu porque fecharam a oficina após a alta temporada do trabalho na costura, que vai até fevereiro; da terceira, porque a dona favorecia à irmã, dando-lhe a maior parte dos pedidos e deixando os outros costureiros sem trabalho. Já na quarta oficina, ela e o marido ficavam sempre de olho nas novas ofertas de trabalho na feira da Rua Coimbra.

Carmen também teve dificuldade de adaptar-se às oficinas, principalmente por ter a filha. Nem todos os donos aceitam trabalhadoras que tenham crianças, por serem menos rentáveis. Assim, Carmen precisa trabalhar mais rápido que os outros costureiros para não perder produtividade quando faz pequenos intervalos para olhar como está a filha. À época da entrevista, estava satisfeita com a oficina onde trabalhava porque não tinha problemas por ser mãe, além de estar perto da escola.

Algumas mulheres não se adaptam ao trabalho duro na costura. Denise, por um problema físico, não pode costurar, então atua como ajudante: faz faxina, despiquetea ${ }^{7}$, dobra peças e ajuda na venda das roupas na Feira da Madrugada, no bairro do Pari, e mora na mesma oficina com os outros costureiros. Brenda também não aguentou o trabalho na costura e era cobrada por "não dar produtividade". Então, trabalha de vendedora em um pequeno box de uma galeria comercial no centro, que revende as peças produzidas na oficina de seu irmão. 
Outras ainda conseguem, após algum tempo trabalhando como costureiras, empregar-se em outros postos. Marcela, após trabalhar muitos anos em oficina, conseguiu alugar um apartamento com a irmã na zona norte da cidade e trabalhar de vendedora, também em um box, no bairro do Brás. Gabriela trabalhou em uma loja de roupas na rua José Paulino, no Bom Retiro, e depois para uma fábrica de tecidos de donos brasileiros e bolivianos, na Moóca. Mesmo assim, ela continua ajudando a família na costura quando é necessário.

Jéssica é a única das bolivianas com quem conversamos que conseguiu terminar o ensino superior, se formando em odontologia. Trabalhava em um consultório na Bolívia e, quando vem ao Brasil apresentar seu filho ao pai, pretende continuar com sua profissão. Porém, a dificuldade com o idioma e a burocracia cara e lenta da revalidação do diploma obrigam-na a ajudar o irmão na oficina, costurando e ajudando a vender na Feira da Madrugada, mesmo após conseguir emprego em São Paulo como ajudante de um dentista boliviano, porque o salário ainda não era suficiente.

Além das mudanças nas trajetórias de trabalho, ou talvez por causa delas, os projetos migratórios também mudam muito ao longo do processo, com a família sempre tendo centralidade na tomada de decisão. Selma, apesar da vontade de voltar para a Bolívia, decide ficar no país por causa das filhas; Carmen também vem para ficar por pouco tempo e, ao ver a possibilidade de trabalhar e cuidar de sua filha, decide ficar. A vontade de voltar também pode estar liga ao arranjo familiar da migrante: Denise, sentindo-se sozinha longe dos pais, tem vontade de voltar depois de poucos meses em São Paulo, mas decide ficar os dois anos a que se havia proposto. Gabriela, por outro lado, já nem quer voltar ao país, porque "todas as pessoas queridas já estão aqui no Brasil".

\section{Relações de gênero nas oficinas de costura}

Como a maioria das bolivianas que se mobiliza para São Paulo passa pelo trabalho na costura, e muitas vezes a possibilidade da sua migração é dada pela indústria da confecção, comentamos agora alguns pontos da relação de gênero nas oficinas. $O$ trabalho na costura é fundamentalmente marcado por um recorte de gênero. Ser mulher é decisivo para o tipo de tarefas e atividades que elas realizam nas oficinas, quais responsabilidades têm e a que tipo de violência estão expostas. Tudo isso redefine as suas trajetórias e percepções subjetivas sobre o processo migratório. Aqui, mobilizamos os depoimentos que ouvimos em campo para tratar de três pontos cruciais das experiências de bolivianas na indústria da confecção paulistana: a divisão do trabalho produtivo dentro das oficinas; as atividades domésticas de reprodução (limpar, cozinhar, lavar roupa, fazer mercado e/ou feira, entre outras), incluída aí a responsabilidade sobre os filhos; e a violência doméstica e sexual.

Ao contrário de outros contextos migratórios, em que homens e mulheres realizam ocupações diversas, bolivianos e bolivianas se inserem (quase, 
excetuadas as cozinheiras e faxineiras, que comentaremos adiante) nos mesmos empregos, qual seja, de costureiros. Cada oficina é composta por uma variedade de máquinas que fazem diferentes tipos de costura (overloque, galoneira e reta), na qual cada costureiro se especializa. A princípio, a oficina contrata o empregado de acordo com a máquina para a qual há necessidade. Segundo Denise e Jéssica, nas máquinas reta e galoneira é necessário pisar com muita força, por isso é assumida preferencialmente por homens, enquanto as mulheres trabalham melhor na overloque, que exige uma pisada mais leve e um manuseio mais ágil.

La mujer pisa más rápido el over [a máquina de overloque], verdad! Para la mujer es más rápido pegar el over que pegar recta [a máquina reta] y galonera [a máquina galoneira]. Tipo, si un homebre hace diez piezas en over la mujer puede hacer un poco más, quince... Bota más rápido. Y le conviene al oficinista tener una overloquista mujer. Os homens mais gostam de recta e as mulheres mais gostam de overloque e galoneira. Eu vi isso. (Denise)

$P$ - Elas costumam escolher mais overloque e galoneira? Por que você acha?

Não sei, eu vi muito de eso. Porque recta parece que é muito pesada, la pisada dela es forte, tem que pisar forte. Me parece que es desse jeito que eles escolhem.

$P$ - E você, trabalha em qual?

Só galoneira e overloque.

$P$ - Você também não gosta da reta?

Não, porque a pisada dela es muito forte, tem que pisar muito forte, aí eu não gosto. E cansa mais. (Jéssica)

É interessante aqui reconhecer como a divisão das tarefas acontece de acordo com os critérios da força física masculina e da agilidade e atenção ao detalhe femininos. Em nossa interpretação, são características constituídas socialmente, muito mais que dados físicos ou biológicos essenciais. No entanto, por conta do maior esforço físico e do tempo que demora para fazer uma peça em cada máquina, há também uma diferença de remuneração, sendo a reta aquela que paga um valor maior por unidade. Denise e Brenda nos disseram que o ganho depende muito mais do tipo de peça costurada que da máquina.

Rectista gana más en la pieza de vestido de fiesta, mientras si es malha gana más el overloquista. Depende, si es tejido 
plano, el que gana es el overloquista. Si es malha también, overloquista. Mas si es vestido de fiesta es el rectista. (Denise)

Porém, em diversas entrevistas, o que aparece como principal fator de remuneração é a produtividade. Quem consegue costurar mais em menor tempo tem maior salário no fim do mês. Brenda conta que, quando tentou trabalhar na reta, ganhava muito pouco porque não dava conta de produzir o suficiente. Ela diz que "solo me aguantaron porque eran mis hermanos", porque qualquer outro dono de oficina a teria expulsado. A cobrança de que os costureiros produzam em grandes quantidades é alta, principalmente porque os donos financiam alimentação e moradia.

Si estás avanzando poco, no sirves. Así te enseñan en la oficina. "No estás dando para yo gane, porque estoy gastando en tu comida, en tu desayuno, tu almuerzo, te doy casa, y no estás rendiendo". (Brenda)

Ainda é preciso observar de perto se há condições para que as mulheres produzam na mesma quantidade que os homens, ou que aprendam o novo ofício no mesmo ritmo. De maneira geral, quando chegam a São Paulo, os migrantes não sabem ainda costurar; no caso dos homens, ao serem recebidos em uma nova oficina, se dedicam a aprender a costurar e recebem um valor menor por peça até se tornarem experientes. Mas, como comentamos, com as mulheres o processo pode ser diferente. Caso seja necessário, assumem o trabalho de faxineira ou cozinheira antes de poder trabalhar na costura, ou dividem as duas atividades até adquirirem experiência, o que leva mais tempo. A realização das atividades domésticas, de forma remunerada ou não, marca a diferença de inserção entre homens e mulheres nas oficinas.

Os arranjos familiares e empregatícios variam muito de uma oficina para outra e dentro da mesma oficina, sendo muitas vezes difícil mapear atividades remuneradas ou feitas a partir de uma ideia de obrigação. Em certos contextos, principalmente em grandes oficinas com muitos costureiros empregados, há uma mulher contratada para cuidar da limpeza dos ambientes comuns e da comida de todos os trabalhadores, cujo salário é o mais baixo da oficina, ocupando a posição mais precarizada. A promessa é que ela aprenda a costurar nos momentos livres, mas apenas se sobrar tempo entre a limpeza e o almoço. Selma descreve sua rotina quando era cozinheira, logo quando chegou ao Brasil, em 2001:

Fazia comida e dormia um pouco, logo fazia alguma coisa, limpava alguma coisa, depois fazia o jantar e dormia de novo. Acordava e fazia café e tudo de novo. Não tinha tempo pra fazer outra coisa, aprender a costurar. Cozinheira era 
cozinheira e costureiro era costureiro, não podia entrar na cozinha e eu não podia entrar na oficina. (Selma)

Em outros casos, as atividades domésticas são tidas como obrigação da mulher e não são remuneradas, ou fazem parte das tarefas gerais de ajudantes, como é o caso de Denise. É o que acontece principalmente em contextos familiares, em que a mãe, por exemplo, cuida da casa (às vezes com ajuda da filha) enquanto o pai e os filhos trabalham na costura. Isso Ihes retira tempo do trabalho produtivo, o que reduz sua produtividade e o salário no fim do mês. Se elas se dedicam a fazer a limpeza apenas nos horários de descanso, perdem os poucos horários livres que podem ter e acabam trabalhando mais e recebendo menos. Isso repõe a dificuldade de acesso ao trabalho e ao dinheiro, como elas viveram na Bolívia, e reforça as contradições de gênero que fundamentam o patriarcado produtor de mercadorias. Com o processo migratório, não se resolvem essas tensões, que muito antes se reproduzem em sentido cada vez mais crítico, submetendo as migrantes a condições precárias de trabalho e de vida - no caso das bolivianas, além do baixíssimo pagamento pelas longas jornadas de costura e das condições insalubres das oficinas, a responsabilidade total pela realização das atividades domésticas. A naturalização destas atividades como femininas é evidente:

Por costumbre, creo que la mujer [trabalha mais], porque tiene que hacer limpieza. Tipo, el hombre deja a su máquina, entonces en fin de semana la mujer tiene que limpiar. Limpia la oficina, despolvorea [tira a poeira que a costura produz], limpia y hace limpieza de toda la casa. (...) Si tiene cocinera, ella hace, y si no, entonces vienen las costureras. El mismo dueño le dice: "tienes que limpiar, tienes que hacer eso". Leviene con el propósito de que eres mujer, tu tienes que demostrar que eres mujercita.

$P$ - E recebem para fazer isso?

No.

P - Fazem por obrigação?

Sí, por género, no sé... (Denise)

Segundo Denise, como agora ela é a única mulher da oficina além de sua tia, Ihe cabe fazer toda a limpeza. $O$ fato de ter sido recebida pelos tios também faz com que sinta certa obrigação sobre a realização desse trabalho, como se devolvesse o favor a eles. Assim, as atividades domésticas serem consideradas naturalmente de atribuição feminina lhes sobrecarrega na realização conjugada do trabalho abstrato com as atividades domésticas. 
As mulheres casadas acabam criando arranjos específicos com os maridos na divisão do trabalho produtivo e tarefas domésticas. Denise chama atenção para esse tipo de arranjo, pensado inclusive pelos donos das oficinas:

$Y$ algunas oficinas prefieren casales que solteros. Tipo, o solteiro te va a hacer problemas, va a tomar, va a pelear, le va a molestar a otra persona, mientras si es casal, le conviene. Si su marido, por ejemplo, sabe hacer galonera y su mujer no, entonces ya tiene una cocinera. (Denise)

Outra característica dessa divisão entre trabalho produtivo e atividades de reprodução é o cuidado com os filhos. Da mesma forma que as mulheres se retiram do trabalho produtivo para realizar as atividades domésticas, se retiram para cuidar dos filhos: se bebês, banhá-los, amamentá-los, trocá-los; se crianças, levar e trazer da escola e fazer-lhes companhia. Quando são mulheres solteiras ou divorciadas com filhos, a mulher precisa sozinha conjugar trabalho produtivo, limpeza do próprio quarto (às vezes das áreas comuns também, como comentamos) e cuidado com as crianças. Carmen conta que, sempre que possível, faz breves intervalos no trabalho da costura para ver como está sua filha, o que está fazendo, se comeu, se fez a lição, mas lamenta não poder acompanhá-la mais. Era também o caso de Jéssica, antes do falecimento de seu filho ${ }^{8}$.

Vale ressaltar que essa é uma condição ocupada apenas pelas mulheres, que sempre ficam com os filhos após uma separação do casal. Acaba colocando as mulheres em situação ainda mais precarizada, já que têm que sustentar a si e aos filhos, lidar com a sobrecarga de trabalho produtivo e atividades de reprodução também de si e das crianças e, além disso, são preteridas pelos donos das oficinas que se queixam de que elas trabalham menos para cuidar dos filhos, porque precisam fornecer alimentação para as crianças, além da mãe, e dar-Ihes um quarto individual, ao invés de dividi-lo com outros costureiros. Isso porque a exclusividade do cuidado feminino sobre os filhos é naturalizada, e a ausência completa do pai é realidade na maior parte dos casos.

Há, ainda, uma forma de violência mais direta e explícita nas oficinas: as agressões físicas e sexuais às mulheres. As primeiras costumam acontecer entre casais, muitas vezes em situações em que o homem está alcoolizado. Nos postos de saúde, segundo as agentes do Programa Saúde da Família que acompanhamos, é comum aparecerem mulheres machucadas afirmando terem "caído da escada" ou "tropeçado", já que o assunto segue sendo um tabu.

As agressões sexuais, principalmente na forma de estupros, também são recorrentes. Esse tipo de ocorrência é reforçado pelo fato de morarem todos dentro da oficina, expondo mais as mulheres. Selma chegou a ter uma oficina de costura com o marido; quando as filhas chegaram aos 12, 13 anos, decidiram trabalhar em casa apenas entre os dois, porque têm medo de que as meninas sejam assediadas por um costureiro que contratem. Acabam perdendo pedidos 
grandes porque apenas ela e o marido não dão conta de costurar tudo, mas ainda assim abrem mão da possibilidade de um ganho maior. Essas agressões não partem apenas de desconhecidos, mas muitas vezes de parentes, como tios, primos, padrinhos e cunhados. Em uma oficina que visitamos em trabalho de campo, duas meninas, ambas sobrinhas do dono, haviam sido "mandadas de volta" para a Bolívia pouco após a sua chegada. A suspeita das agentes de saúde era que teriam sido agredidas pelo tio e engravidado, sendo obrigadas a voltar ao país de origem.

\begin{abstract}
Eu tenho certeza de que muitas mulheres que vão trabalhar nas oficinas de costura sempre por los donos são violadas. Eso sempre escuté, sempre. Por meninas que falam pra mim... (...) eu conheci muito boliviano que en lugar delas, en casa que elas viviam, el dueño de oficina violava elas. Isso eu vi muito... Meninas, hasta filha deles violavam, costureiros, pais, tios, eu vi muito de eso. Eu falei: poxa, eu estou num lugar muito triste. (Jéssica)
\end{abstract}

Como vimos aqui, as mulheres nas oficinas cumprem papeis naturalizados, tidos como essência feminina, desde sempre e para sempre, no que diz respeito a trabalharem em máquinas mais leves e ágeis, realizarem as atividades domésticas e terem responsabilidade sobre o cuidado dos filhos. Na contradição fundante do sistema produtor de mercadorias, cabe a elas a esfera da reprodução, aparentemente dissociada do trabalho e do dinheiro mas fundamental para que existam como tais. Nisso caracteriza-se como patriarcal.

As bolivianas, buscando de alguma maneira reproduzir-se no aprofundamento da crise do trabalho, tornadas por ela obsoletas e obrigadas a se submeter à precarização extrema do emprego na costura simultaneamente à responsabilidade pelas tarefas domésticas, submetem-se ainda a uma renovada possibilidade de agressões físicas e sexuais. Suas trajetórias de migração configuram-se assim a partir de formas econômicas e extra-econômicas de violência particulares de sua condição de gênero. Tais formas de violência aprofundam-se no contexto da crise contemporânea do trabalho, compondo o que chamamos aqui de acirramento das contradições de gênero.

\title{
Migração boliviana para São Paulo e feminização das migrações
}

A partir dos estudos do conceito de mobilidade do trabalho (GAUDEMAR, 1977), entendemos que a migração boliviana para São Paulo é resultado da articulação entre processos contínuos de modernização e mobilização do trabalho, que são em si inseparáveis: modernizar é mobilizar. O histórico da migração boliviana para São Paulo que apresentamos marca alguns momentos 
do processo de modernização boliviano que mobiliza trabalho, simultaneamente, do campo para a cidade, entre cidades bolivianas e para outros territórios, como o brasileiro.

Dentro dos processos de mobilização, o termo feminização das migrações sugere uma transformação de um ou vários fluxos migratórios a partir de um recorte de gênero. $O$ conceito é usado diversamente com sentido quantitativo e qualitativo, muitas vezes sem distinção. Por isso, acreditamos ser necessário delinear que tipo de transformações estão ocorrendo e quais as suas causas. Esta compreensão é fundamental para discernir que lugar ocupam as mulheres nas relações familiares e de gênero em diversos contextos migratórios.

Diante do breve quadro da inserção de bolivianas nas oficinas de costura, começamos a nos perguntar o que então quer dizer a feminização como tendência desse mesmo fluxo migratório e como ela se manifesta empiricamente, elaborando um conjunto de questões sobre em que se constitui o fenômeno. Para uma interpretação quantitativa, podemos perguntar se se trata de um aumento percentual ou absoluto do número de mulheres, que indique um aumento da presença feminina ou uma superação percentual em relação ao número de homens. Os dados de Cymbalista e Xavier (2007), bem como nosso trabalho de campo, indicam que não é o caso. Além disso, detalhe de grande importância, há poucos dados sobre as mulheres na primeira onda migratória boliviana, o que dificulta uma análise puramente quantitativa.

Por outro lado, o chamado fenômeno da feminização pode ser analisado qualitativamente. Poderia tratar-se de uma mudança em relação ao pioneirismo feminino na migração, em que as mulheres deixariam apenas de seguir os maridos ou acompanhar as famílias e passariam a migrar sozinhas, podendo ser as pioneiras em relação a seus grupos familiares. Pode tratar-se, em outra hipótese, de uma reinserção das mulheres na sociedade de destino, ou de uma diferenciação de gênero nas formas de inserção laborais e sociais. Uma feminização do fluxo migratório indica transformações na sociedade de origem, de destino ou em ambas? Dito de outra forma, pergunta-se se há fatores que afetam particularmente as mulheres na Bolívia ou se há condições de inserção em São Paulo que favorecem a presença feminina. Ou, ainda, se a configuração dos grupos familiares e a posição neles ocupada pela mulher têm determinação sobre os projetos migratórios femininos.

Tentaremos responder aos dois conjuntos de perguntas, acessando aquilo que tem se chamado de feminização do fluxo de bolivianos para São Paulo. É preciso, porém, fazer uma advertência. O conceito de feminização das migrações dá a entender que, em algum momento anterior, houve então uma migração essencialmente masculina que agora transforma-se no seu outro. Essa formulação, antes de evidenciar a presença de mulheres nos processos migratórios, a obscurece. Por um lado, apagando a existência de trajetórias de migração feminina anteriores, por outro, pressupondo um sujeito migratório sexualmente 
neutro que, submetido à análise, admite-se como sujeito masculino, já que a sua feminização seria então transformar-se no seu outro. Em ambos os casos, há de se reconhecer que os processos de mobilidade do trabalho não estiveram nunca cindidos de relações de gênero e familiares em que se encontravam os migrantes, e que não é agora que tornam-se esses aspectos determinantes das trajetórias de mobilidade do trabalho.

Vainer (1999), quando convidado a falar justamente sobre novas tendências migratórias do século XXI, tenta discernir entre fatos sociais novos e fatos invisibilizados que são trazidos à superfície. Distingue, portanto, processos que dizem respeito às transformações da realidade social de processos que se referem aos instrumentos teóricos usados para pensar essa mesma realidade. Isso nos ajuda a pensar se a feminização constitui um fato social novo, uma quantidade maior de mulheres migrando, ou uma transformação profunda nas relações de gênero dentro dos fluxos migratórios, ou se constitui um movimento teórico que tira deste lugar do ocultamento o lugar do gênero nos processos de migração e mobilidade do trabalho.

Assim, as perguntas colocadas anteriormente aparecem agora sob novo matiz: trata-se de uma mudança nos fluxos migratórios ou nas análises teóricas que se produzem sobre eles? A feminização constituiria-se como um fenômeno empírico, que trata de mudanças nas experiências sociais de mulheres bolivianas mobilizadas pelo trabalho, ou antes um fenômeno teórico, ligado a transformações da própria teoria, que passa a se interessar por temas como gênero, sexualidade e raça? Isto explicaria, por exemplo, porque não há dados sobre a presença feminina na chamada primeira onda de migração boliviana e porque, a partir dos anos 2010, surgem diversas pesquisas no tema (cf. por exemplo Rezera, 2012; Almeida, 2013; Ribeiro, 2015). Aqui, propomos que os dois processos estão intimamente ligados. Há, por um lado, mudanças significativas em curso em relação à presença feminina e aos papeis de gênero que elas ocupam neste contexto migratório particular; por outro, há também um interesse renovado por parte das ciências humanas.

As pesquisas existentes sobre migração feminina na indústria da confeç̧ão são preciosas na medida em que localizam mulheres latino-americanas e particularmente bolivianas na sua inserção em São Paulo, mas a compreensão aprofundada daquilo que constitui a feminização dos fluxos migratórios depende de um argumento que o compreenda em relação com a totalidade dos processos sociais, e não como particularidade isolada. As transformações a partir da migração precisariam ser vistas em tensão com o movimento da totalidade e, para isso, a reflexão precisa ir além das características internas do grupo migratório. Essa totalidade é por nós entendida como o sistema produtor de mercadorias.

Acontece que esse sistema aprofunda-se cada vez mais em sua própria crise. A concorrência dá o tom da relação entre os vários produtores de mercadorias, impulsionando-os coercitivamente a um aumento da produtividade através 
do desenvolvimento científico e tecnológico. Principalmente após a terceira revolução industrial, aquela que implementa a microeletrônica e a informática como forças produtivas fundamentais, o trabalho humano passa a ser expulso dos processos de produção e tornado supérfluo. Ao mesmo tempo, a utilização valorizadora do trabalho é espremida até o fim do bagaço. Os trabalhadores tornados agora obsoletos são forçados a condições precárias de emprego e de vida, quando não à miserabilização ou ao seu próprio aniquilamento.

O sistema produtor de mercadorias articula contraditoriamente duas esferas, qual sejam, aquela do trabalho, conotada com o universo masculino, e aquela da reprodução da vida, que engloba as atividades domésticas, a família e tudo aquilo que não é trabalho, estando dele dissociado e conotada, portanto, com o feminino. A crise do trabalho colocada nesses termos não tem neutralidade de gênero; é também uma crise da esfera da reprodução e relaciona-se também com os âmbitos doméstico e familiar. O que afirma Scholz (2004) é que a crise assim constituída leva ao acirramento das disparidades sociais constituídas como gênero.

As formas de violência econômica e extra-econômica pesam ainda mais sobre os indivíduos dissociados da esfera do trabalho abstrato, aqueles que não correspondem à sua personificação como o homem, também branco e ocidental, constituindo um acirramento nas contradições de gênero no contexto do sistema produtor de mercadorias. $\mathrm{O}$ aprofundamento dessas tensões abarca ainda as dimensões do racismo, do sexismo e da xenofobia, e aparece empiricamente de maneiras diversas; atendo-nos ao universo das migrações, podemos citar os naufrágios de navios no Mar Mediterrâneo levando refugiados e imigrantes do norte africano para a Europa, o tráfico de mulheres como escravas sexuais em diversos países do mundo, os assassinatos e humilhações na fronteira do México com os EUA, e isso apenas para arranhar a superfície mais trágica.

O contexto de degradação da vida das mulheres na Bolívia faz parte desse quadro. É o contexto de saída. São elas tornadas supérfluas na própria origem, negadas do acesso à terra, ao trabalho e ao dinheiro. A minguada fatia de trabalho que sobra é dividida preferencialmente entre os homens, enquanto às mulheres não caberia mais que cumprir seus papeis naturalizados: as atividades domésticas, o cuidado com os filhos, os trabalhos mais baixos. A exposição das bolivianas à superexploração do trabalho, à violência de gênero das oficinas, à sobrecarga de trabalho produtivo e atividades domésticas é o contexto de inserção.

O que propomos é que o fenômeno de feminização das migrações seja lido como processo social complexo que compreende origem e destino, relações de gênero e formações particulares do patriarcado, a partir de uma relação de totalidade com a crise do trabalho e o acirramento das contradições de gênero como processo social. Nesses termos, a mulher torna-se cada vez mais responsável pelas esferas da reprodução e do trabalho, mesmo que nesta 
última chegue a ocupar os piores postos restantes, e aprofunda-se a violência particular de gênero.

Porém, é preciso reconhecer que a possibilidade de migração das bolivianas é dada também por um ganho de autonomia. Que elas possam sair do país, buscar emprego e sair da tutela masculina - do pai, do marido, dos irmãos faz parte de uma conquista de independência. Mas o cerne da feminização das migrações é a contradição a que chegamos agora: o ganho de autonomia, o escape ao controle familiar e matrimonial, o acesso ao trabalho e ao dinheiro que acontecem no processo migratório levam também a formas renovadas de violência econômica e extra-econômica, como mostramos aqui.

A mobilização feminina para o trabalho expressa o lugar contraditório das mulheres na crise contemporânea: como aumento da autonomia, por um lado, e formas renovadas de violência, por outro. A pesquisa será então capaz de delinear as formas de autonomização das novas migrantes e as formas particulares de violência e contextos históricos de formação do patriarcado que possam relacionar a experiência empírica de migração dessas mulheres com a totalidade do processo social.

Nessa linha, seria de considerar que as condições concretas da vida feminina migrante, configuradas pelo acirramento das contradições de gênero, criam para o Estado um novo problema que compõe o seu papel como gestor da crise, exigindo dele políticas públicas que respondam a este problema. $O$ que sugerimos ainda é que o renovado interesse pelo papel que a mulher ocupa nos fluxos migratórios atuais, para além de uma mudança concreta nas formas de mobilidade femininas, indica também uma crescente demanda da sociedade civil e preocupação do Estado em formular políticas públicas que atendam a essas mulheres como parte de um planejamento de gestão da crise ${ }^{9}$.

Não podemos, aqui, resolver a realidade da chamada feminização das migrações, mas sim entender seu lugar no contexto da crise do trabalho e do acirramento das contradições de gênero. No fundo, queremos entender qual a transformação das relações de gênero no contexto de crise de valorização. Como esse lugar não é único nem universal, tratamos de desenhar o papel concreto que realizam estas mulheres que se mobilizam da Bolívia a São Paulo para se inserir nas oficinas de costura sob as condições de superexploração e violência que enfrentam. 


\section{Notas}

${ }^{1}$ Cada Unidade Básica de Saúde (UBS) tem uma equipe do Programa Saúde da Família (PSF) que se organiza para visitar os domicílios de sua área de atuação. Como os bolivianos moram no local de trabalho, este se configura como domicílio. São visitados pelos agentes de saúde apenas os domicílios que se cadastrarem no programa.

${ }^{2}$ Os nomes das entrevistadas foram alterados para manter a sua privacidade.

${ }^{3}$ O Decreto 21.060, promulgado pelo então presidente boliviano Victor Paz Estesoro, altera a constituição e marca a entrada do modelo neoliberal no país, promovendo uma série de reformas. "Em 1985, o modelo de Capitalismo de Estado foi abandonado, transferindo-se ao setor privado a responsabilidade principal de investimento produtivo. $O$ Estado assumiu o papel de regulador e garantidor da estabilidade macroeconômica e de promotor dos investimentos públicos em saúde, educação, saneamento básico e infraestrutura. Com o Decreto 21.060, também conhecido como a nova política econômica, o investimento privado e a abertura e integração da economia na globalização constituem as novas bases do crescimento econômico" (WANDERLEY, 2009, p. 165). Em 2011, o Decreto 21.060 é derrogado pelo presidente Evo Morales (cf. http://hoybolivia.com/Noticia.php?IdNoticia=47456, acesso em 01/06/2015).

${ }^{4}$ Chegando a 100.000 habitantes/ano em um país de 8,5 milhões de habitantes (VACAFLORES, 2003, p. 2).

5 Dados disponíveis em: <http://estadisticas.cepal.org/cepalstat/WEB_CEPALSTAT/ perfilesNacionales.asp?idioma=e>. Acesso em 11/05/2015.

${ }^{6}$ Principalmente em lojas ou pequenos boxes de galerias comerciais em bairros como Bom Retiro e Brás. Essas lojas são de donos brasileiros ou bolivianos e revendem diretamente roupas produzidas nas oficinas de costura, muitas vezes do mesmo proprietário.

7 Com uma pequena tesoura, corta fiapos de tecido que eventualmente sobram nas roupas depois de já terem sido costuradas.

${ }^{8}$ Seu filho faleceu em junho de 2015, antes da realização de nossa entrevista.

${ }^{9}$ O trabalho de campo realizado nesta pesquisa incluiu também a participação em duas pré-conferências municipais sobre direitos da mulher imigrante, realizadas com o objetivo de levantar propostas para serem levadas à Conferência Municipal da Mulher, realizada em outubro de 2015. Além disso, há grupos organizados atuando sobre a questão da mulher imigrante em São Paulo, cujas ações têm, como parte dos objetivos, pretensão de alcançar alguma instância de gestão pública para a realização de projetos visando esse público (sem especificação de nacionalidade). Entre as propostas levantadas, estão a criação de uma casa de parto com atendimento específico para mulheres imigrantes, tanto no que se refere a práticas tradicionais de parto (como o parto andino, por exemplo) quanto a um atendimento na língua materna da gestante; a criação de creches e vagas para crianças imigrantes; a preparação de funcionários públicos do Sistema Público de Saúde e de setores da burocracia para o atendimento aos imigrantes; entre outras. 


\section{Referências}

ALMEIDA, Táli. As imigrantes sul-americanas em São Paulo: o trabalho feminino na construção de trajetórias transnacionais. 2013. 128 p. Dissertação (Mestrado em Ciência para Análise da Integração da América Latina) - Instituto de Relações Internacionais, São Paulo, 2013.

CYMBALISTA, Renato e XAVIER, lara Rolnik. A comunidade boliviana em São Paulo: definindo padrões de territorialidade. In: Cadernos Metrópole, n. 17, 2007, pp. 119-133.

FAVARETTO, Júlia Spiguel. Descolonizando saberes: Histórias de bolivianos em São Paulo. 2012. 183 p. Dissertação (Mestrado em História Social) - Faculdade de Filosofia, Letras e Ciências Humanas, Universidade de São Paulo, São Paulo, 2012.

FREITAS, Patrícia Tavares de. Imigração e trabalho: determinantes históricas da formação de um circuito de subcontratação de imigrantes bolivianos para o trabalho em oficinas de costura na cidade de São Paulo. XVII Encontro Nacional de Estudos Populacionais, ABEP, Caxambú - MG, 2010.

GAUDEMAR, Jean-Paulo de. Mobilidade do trabalho e acumulação de capital. Lisboa: Estampa, 1977.

NÓBREGA, Ricardo. Migração e mobilização popular: trabalhadores bolivianos na pequena indústria têxtil de São Paulo. In: DOMINGUES, José Maurício et al (org). A Bolívia no espelho do futuro. Belo Horizonte: Editora UFMG; Rio de Janeiro: IUPERJ, 2009, pp. 181206.

REZERA, Danielle do Nascimento. Gênero e trabalho: Mulheres bolivianas na cidade de São Paulo 1980 a 2010. 2012. 209 p. Dissertação (Mestrado em História Econômica) Faculdade de Filosofia, Letras e Ciências Humanas, Universidade de São Paulo, São Paulo, 2012.

RIBEIRO, Clara Lemme. Migração feminina e mobilidade do trabalho: mulheres bolivianas em São Paulo. 2015. 79 p. Trabalho de Graduação Individual (Graduação em Geografia) Faculdade de Filosofia, Letras e Ciências Humanas, Universidade de São Paulo, São Paulo, 2015.

SCHOLZ, Roswitha. A nova crítica social e o problema das diferenças. 2004. Disponível em: http://obeco.planetaclix.pt/roswitha-scholz3.htm. Acesso em 28/02/2014.

SILVA, Sidney Antônio da. Costurando sonhos - trajetória de um grupo de bolivianos em São Paulo. São Paulo, Paulinas: 1997.

VACAFLORES, Victor. Migración interna e intraregional en Bolivia: una de las caras del neoliberalismo. Revista Aportes Andinos. No 7. Globalización, migración y derechos humanos. Outubro 2003.

VAINER, Carlos Bernardo. Migração e mobilidade na crise contemporânea da modernização. In: HEIDEMANN e SILVA (org.) Migração: nação, lugar e dinâmicas territoriais, Coletânea de textos do Simpósio Internacional (São Paulo, 19 a 25 de abril de 1999). São Paulo: Humanitas / USP, 1999, pp. 11-30. 
WANDERLEY, Fernanda. A Bolívia entre a mudança e a inércia: regime de emprego e de bemestar social nos últimos vinte anos. In: DOMINGUES, José Maurício et al (org.) A Bolívia no espelho do futuro. Belo Horizonte: Editoria UFMG; Rio de Janeiro: IUPERJ, 2009, pp. 161-180.

\title{
RESUMO
}

O presente artigo pergunta-se sobre a nova tendência migratória chamada de feminização das migrações, partindo do caso empírico do fluxo de bolivianos para São Paulo. A presença feminina boliviana passa a chamar atenção após a década de 1990, quando começa a aumentar rapidamente. Os motivos de saída da Bolívia das mulheres relacionam-se às dificuldades no acesso à terra, ao trabalho e ao dinheiro. Após a chegada, as trajetórias passam necessariamente pelo emprego na costura, podendo seguir por outros caminhos. Nas oficinas, as mulheres lidam com uma divisão do trabalho produtivo, a realização das atividades domésticas, o cuidado com os filhos e a exposição à violência sexual. Em nossa interpretação, a feminização das migrações constitui-se como um momento da crise do trabalho, tanto em relação à sua mobilização para fora do país de origem quanto em relação à sua inserção. 0 cerne dessa nova tendência é a contradição entre um ganho de autonomia por parte das mulheres e uma exposição a formas renovadas de violência.

Palavras-chave: feminização da migração, bolivianas, crise do trabalho.

\begin{abstract}
The present article discusses the new migratory tendency called feminization of migrations, having the empiric case of the Bolivian immigration flux to São Paulo as its starting point. In the 1990s, Bolivian feminine presence starts attracting attention when it mushrooms. These women's reasons for leaving Bolivia are related to difficulties in accessing land, labor and money. After their arrival, the trajectories necessarily go through working in sewing sweatshops, sometimes leading to different paths. In these sweatshops, women must face the division of productive labor, the performance of domestic activities, children care and an exposition to sexual violence. To our interpretation, the feminization of migrations constitutes a moment of a labor crisis, regarding their mobilization outside their native country as much as their insertion. This new tendency's core is the contradiction between an autonomy gain and an exposition to renewed forms of violence.
\end{abstract}

Key-words: migration of feminization, bolivian, labor crisis. 